\title{
ESTEEM and FACTS: Creative Ways to Teach Healthy Lifestyles to Youth from Diverse Backgrounds
}

\author{
Tary J. Tobin \\ College of Education, University of Oregon Eugene, Eugene, USA. \\ Email: ttobin@uoregon.edu \\ Received June $8^{\text {th }}$, 2011; revised June $27^{\text {th }}, 2011$; accepted July $7^{\text {th }}, 2011$.
}

\begin{abstract}
Two health education programs illustrating different ways to engage youth from racially and ethnically diverse backgrounds in positive youth development lessons and activities are described for practitioners in schools and community agencies. Both programs were developed in collaborative efforts between public school health teachers and community organizations and resulted in abstinence education curricula suitable for use in either schools or community agencies. Both programs were effective with youth from different racial and ethnic backgrounds in promoting setting wholesome personal goals, developing prosocial and healthy relationships, and avoiding risky behaviors such as premature sexual activity or abuse of alcohol and illegal drugs. Federal programs designed to prevent teen pregnancy facilitated the development and evaluation of both programs. ESTEEM was developed in Texas at the Longview Wellness Center and FACTS was developed in Oregon by Northwest Family Services.
\end{abstract}

Keywords: Health Education, Teaching Methods, Racial and Ethnic Diversity, Teen Pregnancy Prevention

\section{Introduction}

Unintended teen pregnancies are serious problems for the following reasons: 1) early prenatal care often is not received; 2) the fetus often is exposed to alcohol, tobacco, and drugs; 3 ) about half of all unintended pregnancies lead to abortions; 4) it is a risk factor for low birth weight, death in the first year of life, and neglect or abuse; 5) maternal depression is may occur; 6) physical abuse of the mother is a serious risk; 7) the couple's relationship may be negatively affected; and 8) both mother and father may experience financial difficulties and difficulty in achieving educational and career goals (Brown \& Eisenberg, 1995). Health educators need creative ways to help youth form intentions that will guide their behaviors, form habits associated with healthy lifestyles, and enable attainment of goals of completing school and preparing for a successful personal and future family life. ESTEEM and FACTS are two such creative ways. These two health education programs are described to show two different ways to engage youth in positive youth development lessons. Both programs were effective with youth from different racial and ethnic backgrounds in promoting setting wholesome personal goals, developing prosocial and healthy relationships, and avoiding risky behaviors.

\section{ESTEEM}

The East Texas Abstinence Program (ETAP) started in the 2001-2002 academic school year with support from the Longview Wellness Center, a medical clinic (now called Wellness Pointe) and the Texas Department of Health. During the 2002-2003 and 2003-2004 school years, ETAP was a Special Project of Regional and National Significance grant recipient. During the 2004-2005, 2005-2006, 2006-2007, and 2007-2008 school years, ETAP was a Community-Based Abstinence Education program under the Administration for Children and Families (ACF) of the federal Department of Health and Human Services.

ETAP was designed to prevent teen pregnancy and sexually transmitted disease while helping youth from diverse racial and ethnic backgrounds make physically, mentally, and emotionally healthy decisions. The demographic characteristics of the students who participated in this program varied slightly over the years but typical percentages were White 54\%, African American $23 \%$, Hispanic ${ }^{1} 18 \%$, Other $4 \%$, Asian $0.84 \%$, and Native American $0.56 \%$. The total number of participants was more than 2000 most years.

Methods used included 1) health education classes in public schools; 2) programs, activities, and special events in communities and alternative schools; 3) meetings of a supportive coalition of youth and adults; and 4) a multimedia campaign using a range of methods of outreach, including entertaining and informative Public Service Announcements (PSAs) for radio and television, billboards, car bumper stickers, and a Web site, http://www.virginityrules.com, where copies of PSAs, billboards, and other information for youth, parents, schools, community members, and the public in general are posted. With headquarters in Longview, Texas, abstinence education classes were provided to schools in multiple counties in the eastern part of Texas (e.g., Camp County, Gregg, Harrison, Marian, Panola, Rusk, Smith, and Upshur).

ETAP offered programs suitable for upper elementary, middle school, and high school students. Initially, before ESTEEM was developed in Texas, ETAP used a curriculum developed in

\footnotetext{
${ }^{1}$ At the time of the development of ESTEEM, the funders allowed this type of demographic breakout. The common current requirements to first ask about Hispanic or Latino ethnicity and then ask about race was not yet in place.
} 
Oregon, Family Accountability Communicating Teen Sexuality (FACTS; Fuller \& Asato, 1998; Fuller, Denman, \& McLaughlin, 1997; Fuller \& McLaughlin, 1998). Annual reports from an independent evaluator that included results from surveys were used to guide program development over the years (e.g., Tobin, 2002, 2003). The younger students participated in a character-based health education program that did not specifically address sexuality but was designed to serve as a foundation for such lessons at higher grade levels (Fuller et al., 2000a, 2000b). ETAP worked with local schools and communities to develop ESTEEM: An Abstinence Based Curriculum for Grades 6 - 9 (East Texas Abstinence Program, 2006b) and other materials for the EQUIP (East Texas Abstinence Program, 2006a) series for different grade levels.

The ESTEEM curriculum uses workbooks with facts and figures, questions and answers, demonstrations, games, and activities to engage students. Materials to help the teachers also are provided as well as educational incentives, such as book marks, contract cards, and stickers. The contract cards are about the size of a credit card and they are type of pledge to be sexually abstinent before marriage. One ETAP youth leader reports that on a return visit to a school about a year after he had made a presentation and handed out these cards, he decided to ask if anyone still had the card he had given last year. Thinking that no one would have one, he offered to give 5 dollars to the first person who could show him that they still had the card. He was glad that he said the first person because students were keeping the cards in their wallets and it could have been quite an expensive day for him if he had to pay everyone who kept their cards! However, this incident suggests that the cards were a worthwhile part of the program.

The ten lessons in the ESTEEM curriculum cover the following topics:

1) Finding My Way: a) my values and beliefs, b) short and long term goals, c) commitment and dreams.

2) The Media and Me: a) facts about the media, b) sex sells: Its influence on you, c) internet safety guidelines.

3) STDs Are Not for Me: a) What are STDs? b) Can they be prevented? c) Braniac Quiz.

4) What about Teen Pregnancy? a) What if? Options and choices, b) the truth for girls and guys, c) life of a teen mom.

5) What does the law say about sex? a) learn to protect yourself, b) legal consequences of underage sex, c) you be the judge.

6) Feeling the Squeeze: a) everybody is doing it-peer pressure, b) conflict resolution, c) come back lines.

7) Drugs and Alcohol: a) real friends and drug use, b) effects of alcohol and drug use, c) case study: Nicole and Trisha.

8) Having Freedom with Friends: a) healthy relationships, b) establishing personal boundaries, c) positive peer power.

9) Relationships: a) dating through the years, b) boundaries in the dating relationship, c) my individual contract.

10) Setting Your Goals: a) reviewing your goals? b) your big day, c) crossword puzzle.

The annual evaluations typically found that pre- to post-intervention changes were statistically significant $(p<.01)$, with positive changes in areas such as the proportion of adolescents who 1) understand that abstinence from sexual activity is the only certain way to avoid out-of-wedlock pregnancy and sexually transmitted disease; 2) report they have the refusal or as- sertiveness skills necessary to resist unwanted sexual advances; 3) commit to abstain from sexual activity until marriage; 4) intend to avoid situations and risk behaviors, such as drug use and alcohol consumption, which make them more vulnerable to sexual advances. The ETAP program made good use of formative evaluation over the years and continually improved their program, as illustrated Figure 1, showing post-intervention responses over the years.

\section{Concurrent Validity}

The ESTEEM curriculum for $7^{\text {th }}$ and $8^{\text {th }}$ graders was compared with an established, traditional abstinence education curriculum (FACTS) that was already being used by many schools, especially in Texas and in Oregon (Tobin, 2007). The participating students in this descriptive study reported diverse racial and ethnic backgrounds, with the three largest groups being White (54\%), Black (23\%), and Hispanic (18\%). A multiple regression analysis indicated that race/ethnicity, as well as type of curriculum used, accounted for some of the variance in preto post-intervention changes.

Both groups of $7^{\text {th }}$ and $8^{\text {th }}$ grade students, the ones using the EQUIP materials and the ones using the FACTS materials, on average, improved after the abstinence education lessons in attitudes, intentions, and perceptions. These were measured in surveys containing several scales, such as the Future Orientation scale, which is explained below:

Future Orientation (FO) Scale

- Indicates awareness of the value of abstinence for attainment of future goals

- 3 questions (goals for education, future marriage and family, and career/job)

- Low scores indicate attitudes favorable to abstinence

- Cronbach's Alpha = .82

The questions used the following format:

Do you think that abstinence (not having sex) as a teen would make it easier for you to get a good education in the future?

1) It would make it a lot easier.

2) It would make it a little easier.

3) It wouldn't make any difference.

The EQUIP group consisted of 750 students in $7^{\text {th }}$ and $8^{\text {th }}$ grade from 5 schools in 4 counties in East Texas: Camp County, Gregg, Harrison, and Rusk County. The FACTS group consisted of 1160 students in $7^{\text {th }}$ and $8^{\text {th }}$ grade from 15 schools in 7 counties in East Texas: Gregg, Harrison, Marian, Panola, Rusk, Smith, and Upshur Counties. The average age, in years, for the FACTS group was $13.08(S D=1.27)$; for EQUIP it was 13.01 $(S D=1.53)$, not a statistically significant difference $(p<.05)$. Females made up $52 \%$ of the FACTS group and $47 \%$ of EQUIP, also not a statistically significant difference $(p<.05)$.

Using multiple linear regression, post-intervention scale scores were predicted on the basis of 1) race/ethnicity, 2) pre-intervention scores, and 3) type of curriculum used (i.e., "group" being EQUIP or FACTS). Controlling for race/ethnicity first, and then for pre-intervention score, group made a statistically significant $(p<.05)$ difference for Future Orientation (FO), as shown in Table 1.

In an Analysis of Variance test (using the PROC NPAR1 WAY procedure in SAS 9.1 for Windows), for both groups, the average on the FO Scale changed in the intended direction 


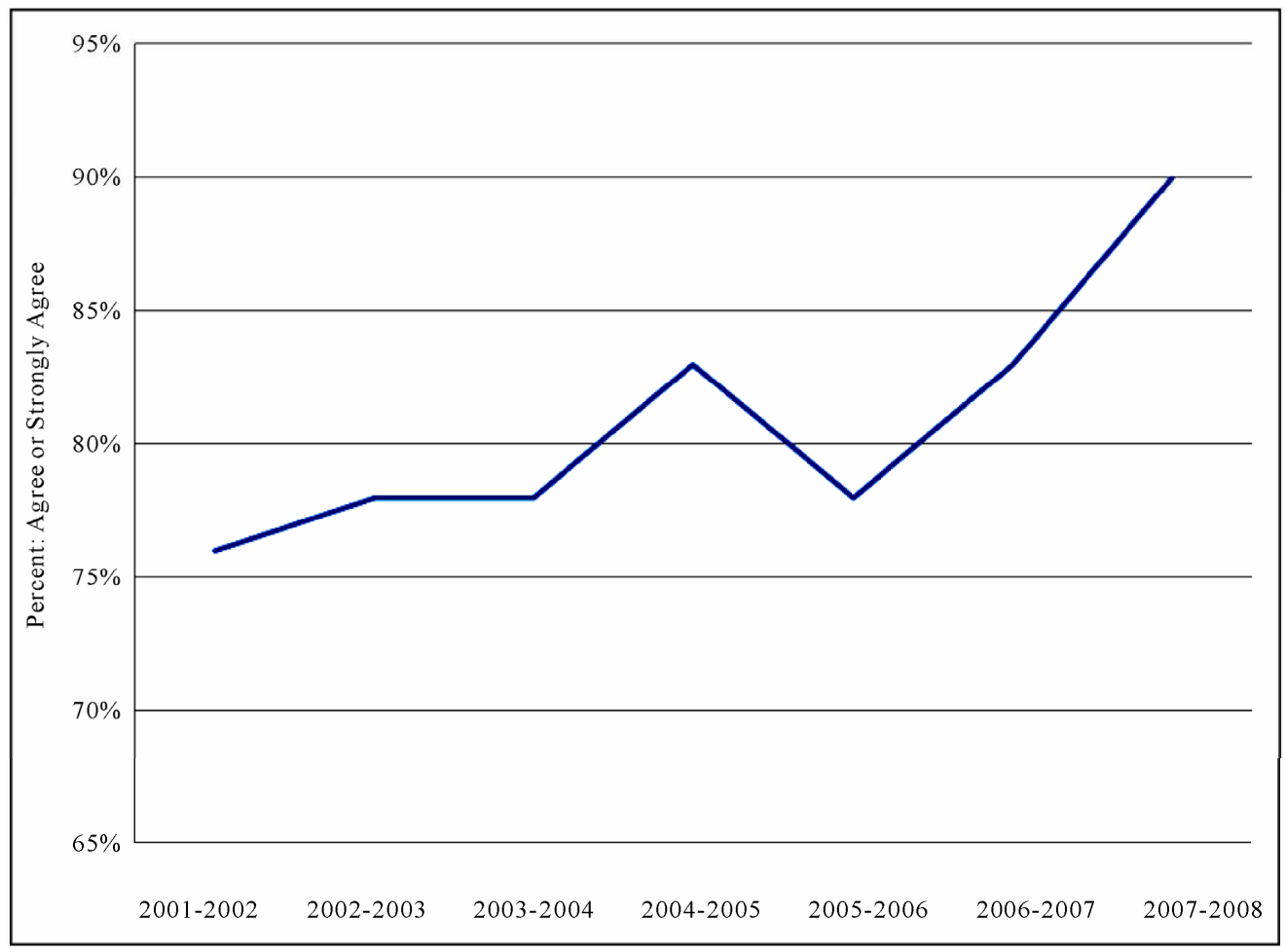

Figure 1.

Percent who agree or strongly agree that "The best way for teenagers to avoid unintended pregnancy, HIV/AIDS and other sexually transmitted infections is to wait until they are married before having sex."

(down) after the intervention. The group averages were not statistically significantly $(p<.05)$ different at Time 1 (preintervention) but were post-intervention. Both groups improved. The EQUIP group average changed more than the FACT average did. On the FO Scale, the difference between Time 1 and Time 2, group differences, and the interaction between time and group, were all statistically significant, as shown in Table 2.

Although both curricula were beneficial, the ESTEEM curriculum may be particularly useful for schools in Texas servingstudents from diverse backgrounds. Positive changes were most noticeable for the African American and Hispanic students using ESTEEM.

Figure 2 illustrates the average changes for African American students who responded to the Future Orientation (FO) marriage question on both the pre- and post-intervention questionnaire. Results were similar for the other FO questions and for Hispanic students.

\section{Limitations}

The study was limited in that random assignment was not used and although the groups were similar in many ways, differences that may have affected the results did exist, such as previous abstinence education classes (more common for the FACTS group). Another factor to consider was that in the Texas implementation, the full FACTS program (to be described below) as it is implemented in Oregon was not used. That is, the FACTS printed materials (text books) were used but peer leaders, socio-dramas, and other non-printed elements of the Oregon style FACTS program were not used in Texas.
Table 1.

Summary of simultaneous regression analysis for variables predicting post-intervention future orientation (FO) score.

\begin{tabular}{cccc}
\hline Variable & $B$ & $S E$ B & $\boldsymbol{\beta}$ \\
\hline Race/Ethnicity & 0.12 & 0.21 & $0.06^{*}$ \\
Pre-Intervention Score & 0.61 & 0.02 & $0.64^{*}$ \\
Group & 0.25 & 0.08 & $0.06^{*}$ \\
\hline
\end{tabular}

${ }^{*} p<.001$. Note. $R^{2}=.41(F[3,1806]=418.60), p<.001$ for predictor variables.

Table 2.

Future orientation: repeated measures analysis of variance.

\begin{tabular}{ccc}
\hline Source & df & F \\
\hline \multirow{3}{*}{ Between Subjects } & $3.86^{*}$ \\
Error & 1 & \\
& $1849(6.95)^{\mathrm{a}}$ & \\
Time & Within Subjects & $58.21^{* *}$ \\
Time x Group & 1 & $4.26^{*}$ \\
Error (Time) & $1849(1.56)^{\mathrm{a}}$ & \\
\hline
\end{tabular}

${ }^{a}$ Values enclosed in parenthesis represents mean square errors. ${ }^{*} p<.05 .{ }^{* *} p$ $<.001$. Note: Dunnett's $t$ indicates that the group averages were not statistically significantly different at Time 1 but were at Time $2(p<.05)$. 


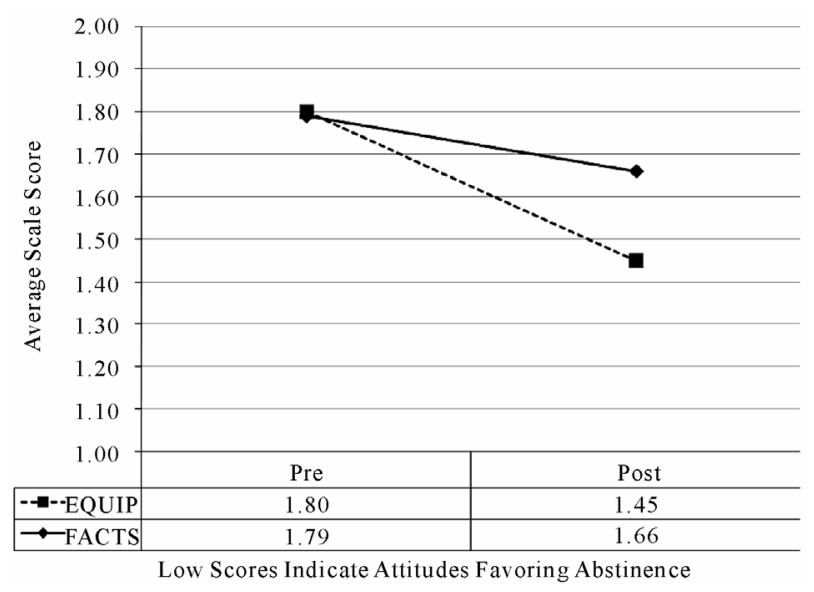

Figure 2.

African American students' average responses to the FO marriage question.

\section{FACTS: Oregon Style Implementation}

The FACTS curriculum (Fuller \& McLaughlin, 1998), part of the Youth Solutions program, was developed by Northwest Family Services (NWFS), a non-profit, non-sectarian organization based in Portland, Oregon, with partial funding from a series of grants from the federal Office of Adolescent Pregnancy Programs (OAPP), over more than 15 years. Every year, an independent evaluation was conducted and results were used to refine the program (e.g., Tobin, 2000, 2001; Tobin \& Sugai, 1998; 1999; Weed, 1993, 1995). Most recently, the evaluation used the Adolescent and Family Life (AFL) Baseline and Follow Up Questionnaires for prevention programs and a psychometric evaluation of this questionnaire was conducted, one of the few efforts to establish the reliability and validity of an abstinence education measure (Vincent, Xue, Tobin \& Fuller, 2010).

FACTS was designed to teach sexual abstinence to middle school students in a clear, direct, and unequivocal way by using multiple strategies including 1) up to 15 lessons in health classes in public schools with topics related to goal setting, healthy choices, and positive relationships; 2) trained staff from a community agency who work with peer leaders, parents, and teachers; 3) festivals and cultural events; and 4) high school peer leaders who help interactive lessons in middle schools, such as the development of multi-media materials, and who act in socio-dramas. A social marketing strategy included billboards in the project area as well as airing English and Spanish-language PSAs, which referred parents to a bilingual website, www.talktothem.org. A website to engage the youth participants also was developed, http://www.itslegit.org.

Positive youth development (Catalano, Berglund, Ryan, Lonczak, \& Hawkins, 1998; Benson, Scales, Hamilton, \& Sesma, 2006; Greenberg et al., 2003) principles provided a foundation for the emphasis in the FACTS program on activities and lessons to enhance self-efficacy, positive identity, and pro-social behaviors, which are all critical elements associated with abstinent behavior. The benefits of delaying sexual involvement include avoiding sexually transmitted infections, unintended pregnancy, and the negative experiences related to having multiple sexual partners over time (Cokler, 1994; Genuis \& Genuis, 2004; Guilamo-Ramos, Jaccard, Dittus, Gonzalez, \& Bouris, 2008; James, Montgomery, Leslie, \& Zhang, 2009; Jemmott, et al., 2010; Mohn, Tingle, \& Finger, 2003; O'Donnell, O'Donnell, \& Stueve, 2001; Romeo \& Kelly, 2009). A study with a one year follow up of an abstinence program's impact on sexual behavior found a reduction in sexual initiation. Virgin students in the experimental group were less likelyabout half as likely - to initiate sexual intercourse as the virgins in the comparison groups during the year following the intervention (Weed, Ericksen, Lewis, Grant, \& Wibberly, 2008).

A particular target population for some of the FACTS projects was the rapidly growing Latino population in Oregon. The Spanish version is called "DATOS." For Latinas, more than for other ethnic groups, school dropout is associated with teen pregnancy (Manlove, 1998). The demographic characteristics of the students who participated in the surveys used in the evaluations of the FACTS program in Oregon varied over the years but typical percentages were White $78 \%$, Hispanic or Latino 9\%, Other 5\%, Asian 4\%, African American 2\%, and Native American 2\%. Annually, the number of participants in the surveys for the evaluation of FACTS varied from about 1,000 to more than 2,000. More youth, particularly more Latino youth, were actually served than were available for both the pre- and the post-intervention surveys. The FACTS/DATOS curriculum also was used successfully in a program in New York State with at-risk urban youth from diverse racial and ethnic backgrounds (Carter-Jessop, Franklin, Heath, JimenezIrizarry, \& Peace, 2000).

The FACTS/DATOS curricula, when used as a part of the full Youth Solutions intervention, was particularly successful with the Latino population (Tobin \& Sánchez, 2007). By the end of the program, $69 \%$ of participants reported that they intend to be sexually abstinent until marriage. In addition, Latino parents reported being more comfortable in talking with their child about sex and that their child's values were more in agreement with their own values after the intervention.

The Youth Solutions project offered different levels of intervention: socio-dramas in both English and Spanish, (Promises, Truth or Consequences, and Encuentros-see http://www.itslegit.org/whats-up.html), the FACTS/DATOS curricula series, and peer leaders. Under the direction of NWFS staff and school faculty, the high school peer leaders gave personal testimonies about abstinence, conducted role plays, reinforced refusal skills, gave examples on how to navigate high school, and answered the questions of middle school students. Training for peer leaders followed procedures documented in a manual (Fuller \& Bankston, 2002). These leaders also assisted with positive youth development activities such as organizing soccer tournaments and Latino festivals. NWFS worked with middle school students to develop PSAs, posters, songs and rap lyrics, and newsletter articles that supported abstinence. These were submitted in a contest with the winners selected at the end of the school year. NWFS staff members provided in-service training for teachers and counselors to implement abstinence education. They also recruited, selected, trained, and supervised teenage actors and peer leaders. Language-specific services were offered in Spanish during school and in after-school Latino clubs. Motivational speakers were used to reinforce the message. 
In the early years of the development of this program, a series of studies (e.g., Tobin, 2002, 2003) compared the effect of different “doses,” from 1) minimal, just the socio-drama; to 2) medium, the socio-drama plus the FACTS lessons in school but without the peer leaders or the interactive multi-media projects; and 3) maximum, the full or "intensive" Youth Solutions program with all materials and activities (i.e., socio-dramas, FACTS lessons, peer leaders, interactive multi-media projects, cultural festivals, and parent support). For the intensive intervention, a statistically significant $(p<.01)$ increase occurred in the percentage of students expressing the intention to remain abstinent until marriage, with rise from 50 percent before the intervention to 70 percent afterwards. The brief intervention also showed improvement, but it was not as impressive an improvement (Fuller \& Tobin, 2005).

\section{Conclusion}

In our society, it is common to hear jokes being made at the expense of proponents of abstinence education by cynical individuals who suggest that "everyone is doing it" and who do not believe there is any point in encouraging teens to practice sexual abstinence. However, the students, teachers, parents, and developers and implementers of ESTEEM and FACTS know that for many youth, these programs are life changing. The following description of a youth's experiences provides a clear view of how this type of intervention can have a powerful impact:

I had never really thought about abstinence education or even heard of it, really. ... I auditioned [to act in a sociodrama] ... and almost overnight I started learning about abstinence. We perform a play, also called "Promises," which addresses STIs and other sex-ed ideas, and abstinence is definitely the biggest message. ... We talk about waiting, and we give our own testimonials about staying abstinent, and the financial consequences of having a kid ... I think a lot of their excitement comes from our serious, but relaxed, approach. We ... let them get their giggles out, but the second time we explain how serious these real-life situations can be. We ... make them assert themselves and exercise good refusal skills. They see that you can face these pressures from your best friend, or boyfriend or girlfriend, and suddenly you see them getting more confident and really responding to abstinence, a concept they can take pride in.

(Northwest Family Services' Drama Troupe Member and FACTS' Peer Leader).

\section{References}

Benson, P. L., Scales, P. C., Hamilton, S. F., \& Sesma Jr., A. (2006). Positive youth development: Theory, research, and applications. In R. M. Lerner, \& W. Damon, (Eds.), Handbook of child psychology (6th ed.): Vol. 1, Theoretical models of human development. (pp. 894-941). Hoboken, NJ: John Wiley \& Sons, Inc.

Brown, S. S., \& Eisenberg, L. (1995). The best intentions: Unintended pregnancy and the well-being of children and families. Washington, D.C.: National Academies Press.

Carter-Jessop, L., Franklin, L. N., Heath, J. W., Jimenez-Irizarry, G., \& Peace, M. D. (2000). Abstinence education for urban youth. Journal of Community Health, 25, 293-304. doi:10.1023/A:1005160326267

Catalano, R. F., Berglund, M. L., Ryan, J. A. M., Lonczak, H. S., \&
Hawkins, J. D. (1998). Defining and evaluating positive youth development. In Positive youth development in the United States: Research findings on evaluations of positive youth development programs. URL (last checked on 5 June 2011)

http://aspe.hhs.gov/hsp/PositiveYouthDev99/chapter2.htm

Cokler, A. L., Richter, D. L., Valois, R. P., McKeown, R. F., Garrison, C. Z., \& Vincent, M. I. (1994). Correlates and consequences of early initiation of sexual intercourse. Journal of School Health, 64, 372-377. doi:10.1111/j.1746-1561.1994.tb06208.x

East Texas Abstinence Program. (2006a). EQUIP. Longview, TX: Author.

East Texas Abstinence Program. (2006b). ESTEEM: Encouraging students to embrace excellent marriage. Longview, TX: Longview Wellness Center.

Fuller, R., \& Asato, A. (1998). I'm in charge of the facts. Portland, OR: Northwest Family Services.

Fuller, R. \& Bankston, C. (2002). Peer leader training: A youth solutions manual. Portland, OR: Northwest Family Services.

Fuller, R., Denman, H., \& McLaughlin, J. (1997). How to teach the facts of life. Portland, OR: Northwest Family Services.

Fuller, R., \& McLaughlin, J. (1998). Family accountability: Communicating teen sexuality (FACTS). Portland, OR: Northwest Family Service.

Fuller, R., McLaughlin, J., Monahan, P., Bankston, C., Hayes-Barba, R., Taylor, R., \& Fuller, S. (2000a). Facts and friends. Portland, OR: Northwest Family Service.

Fuller, R., McLaughlin, J., Monahan, P., Bankston, C., Taylor, R., \& Fuller, S. (2000b). Facts about me. Portland, OR: Northwest Family Service.

Fuller, R., \& Tobin, T. J. (2005, November 3). Northwest Family Services' Youth Solutions: A comparison of brief and intensive abstinence education interventions. Poster presented at the Abstinence Education Evaluation Conference hosted by the Office of Population Affairs and co-sponsored by the Administration for Children and Families, Baltimore.

Genuis, S. J. \& Genuis, S. K. (2004). Managing the sexually transmitted disease pandemic: A time for reevaluation. American Journal of Obstetrics and Gynecology, 191, 1103-1112. doi:10.1016/.ajog.2004.03.019

Greenberg, M. T., Weissberg, R. P., O’Brien, M. U., Zins, J. E., Fredericks, L., Resnik, H., \& Elias, M. J. (2003). Enhancing schoolbased prevention and youth development through coordinated social, emotional, and academic learning. American Psychologist, 58, 466474. doi:10.1037/0003-066X.58.6-7.466

Guilamo-Ramos, V., Jaccard, J., Dittus, P., Gonzalez, B., \& Bouris, A. (2008). A conceptual framework for the analysis of risk and problem behaviors: The case of adolescent sexual behavior. Social Work Research, 32, 29-45.

James, S., Montgomery, S. B., Leslie, L. K., \& Zhang, J. (2009). Sexual risk behaviors among youth in the child welfare system. Children and Youth Services, 31, 1127-1134.

Jemmott, J. B., Jemmott, L. S., \& Fong, G. T. (2010). Efficacy of a theory-based abstinence-only intervention over 24 months: A randomized controlled trial with young adolescents. Archives of Pediatrics and Adolescent Medicine, 164, 152-159. doi:10.1001/archpediatrics.2009.267

Manlove, J. (1998). The influence of high school dropout and school disengagement on the risk of school-age pregnancy. Journal of Research on Adolescents, 8, 187-220. doi:10.1207/s15327795jra0802 2

Mohn, J. K., Tingle, L. R. \& Finger, R. (2003). An analysis of the causes of the decline in nonmarital birth and pregnancy rates for teens from 1991 to 1995. Adolescent and Family Health, 31, 39-47.

O’Donnell, L., O’Donnell C. R., \& Stueve, A. (2001). Early sexual initiation and subsequent sex-related risk among urban minority youth: The Reach for Health Study. Family Planning Perspectives, 33, 268-275.

Romeo, K. E., \& Kelly, M. A. (2009). Incorporating human sexuality content into a positive youth development framework: Implications 
for community prevention. Children and Youth Services, 31, 1001-1009. doi:10.1016/j.childyouth.2009.04.015

Tobin, T. J. (2000). 1999-2000 Northwest Family Services' Youth Solutions: FACTS and Promises. Evaluation Report to the Office of Adolescent Pregnancy Programs. Eugene, University of Oregon.

Tobin, T. J. (2001). 2000-2001 Northwest Family Services' Youth Solutions: FACTS and Promises. Evaluation Report to the Office of Adolescent Pregnancy Programs. Eugene, University of Oregon.

Tobin, T. J. (2002). East Texas abstinence program, evaluation report, 2001-2002. Eugene, OR: University of Oregon.

Tobin, T. J. (2003). East Texas abstinence program, evaluation report, 2002-2002. Eugene, OR: University of Oregon.

Tobin, T. J. (2007). East Texas Abstinence Program Evaluation Report: 2006-2007. Report submitted to the Administration for Children and Families' Community-Based Abstinence Education Programs. Eugene, University of Oregon, College of Education.

Tobin, T. J., \& Sánchez, F. J. (2007). Community programs for Latino families and school programs for all students: Effects on attitudes and skills that support abstinence. Paper presented at the $2^{\text {nd }}$ Annual Abstinence Education Evaluation Conference hosted by the Office of Population Affairs and co-sponsored by the Administration for Children and Families, Baltimore. URL (last checked on June 5, 2011) http://www.ent-s-t.com/ESTOPA/presentations/Tobin.pdf
Tobin, T. J., \& Sugai, G. (1998). Northwest Family Services' Youth Solutions: FACTS and Promises. 1997-1998 Evaluation Report to the Office of Adolescent Pregnancy Programs. Eugene, University of Oregon.

Tobin, T. J., \& Sugai, G. (1999). Northwest Family Services’ Youth Solutions: FACTS and Promises. 1998-1999 Evaluation Report to the Office of Adolescent Pregnancy Programs. Eugene, University of Oregon.

Vincent, C. G., Xue, L., Tobin, T. J., \& Fuller, R. (2010). A psychometric evaluation of the youth surveys used in the Oregon youth development project. Eugene: University of Oregon, College of Education, Educational and Community Supports.

Weed, S. E. (1993). FACTS project year-end evaluation report, 19921993. Unpublished manuscript prepared for the U. S. Office of Adolescent Pregnancy Programs. Kearns, UT: The Institute for Research and Evaluation.

Weed, S. E. (1995). FACTS project year-end evaluation report, 1993-1994. Unpublished manuscript prepared for the U. S. Office of Adolescent Pregnancy Programs. Kearns, UT: The Institute for Research and Evaluation.

Weed, S. E., Ericksen, I. H., Lewis, A., Grant, G. E., \& Wibberly, K. H (2008). An abstinence program's impact on cognitive mediators and sexual initiation. American Journal of Health Behavior, 32, 60-73. 